\title{
Search Unstructured Data Performance in P2P Networks Based on User Interest Model
}

\author{
K. Shanmugapriya, I. Mary Linda, Kavitha G
}

\begin{abstract}
Distributed (P2P) systems build up approximately coupled application-level overlays on high of the web to encourage affordable sharing of assets. They'll be generally delegated either organized or unstructured systems. while not requesting requirements over the topology, unstructured $\mathrm{P2P}$ systems is made appallingly speedily and ar so contemplated fitting to the web air. Be that as it may, the arbitrary pursuit strategies received by these systems now and then perform ineffectively with a larger than usual system Size. during this paper, we tend to search for to help the pursuit execution in unstructured P2P arranges through misusing clients' basic intrigue designs caught among a likelihood theoretic structure named the client intrigue model (UIM). an exploration convention and a directing table change convention ar increasingly arranged in order to speed up the hunt technique through self sorting out the P2P organize into somewhat world. Each hypothetical and test examination are Conducted and incontestable the viability and strength of our methodology.
\end{abstract}

Keywords: UIM- User Interest Model, Search Protocol, Routing table change protocol, economical performance in massive network size

\section{INTRODUCTION}

The chase execution in unstructured P2P frameworks is effectively improved through mishandling the applied number juggling models over customer's essential interest. to help the request execution in unstructured P2P frameworks reinforced the fundamental excitement of the customers. regionally shared resources of a partner is researched to coordinate the scattered resource disclosure strategy consequently overhaul the general resource exposure execution in unstructured P2P frameworks. Uses the User Interest Model (UIM) maintained the general probabilistic mechanical assembly named Condition Random Fields (CRF) to show customer's various points of interest. In case the chase content is out there in neighborhood friend, by then it'll recoup the substance of the record from nearby structure. Else it propels the request to its neighboring Peers. If the neighboring companion have the request content, by then it response to looking out friend. One major challenge of $\mathrm{P} 2 \mathrm{P}$

Revised Manuscript Received on December 11, 2019

* Correspondence Author

K. Shanmugapriya, Department of Computer Science and Engineering, Bharath Institute of Higher Education and Research, Chennai, Email: shanmugapriyabiher@gmail.com

I. Mary Linda, Department of Computer Science and Engineering, Bharath Institute of Higher Education and Research, Chennai. Email: catchlin.18@gmail.com

Kavitha G, Department of Computer Science and Engineering, Bharath Institute of Higher Education and Research, Chennai, Email: kavithag90@gmail.com

frameworks is to achieve commonsense resources divulgence. Inside the composition, a couple P2P frameworks are orchestrated with a ultimate objective to beat this test. Those frameworks is commonly assembled into 2 classes, to be explicit, composed $\mathrm{P} 2 \mathrm{P}$ frameworks maintained an appropriated hash table (DHT) and unstructured P2P frameworks supported distinctive unpredictable interest techniques (e.g., flooding). while not compelling any mentioning impediments over the topology, unstructured $\mathrm{P} 2 \mathrm{P}$ frameworks is made dreadfully rapidly and have so pulled in generously more sensible use inside the net than the sorted out frameworks. Companions in unstructured frameworks ar usually named outwardly debilitated, since they're at times unequipped for dire the likelihood that their neighbor partners will satisfy any advantage questions. accomplice degree annoying consequence of this is normally that the intensity of passed on resource divulgence systems can ought to be undermined. In apply, resources shared by a buddy normally show some applied number juggling models. the normal course of action of this paper is that the applied number juggling models over regionally shared resources of a companion is explored to deal with the flowed resource disclosure strategy therefore update the general resource exposure execution in unstructured $\mathrm{P} 2 \mathrm{P}$ frameworks. 3 key examination issues are known and considered during this paper to save lots of companions from their visual disfigurement. For direct talk, only 1 basic kind of benefits, to be explicit, data records will be thought about during this paper.

Research issue oversees discretional request. unstructured P2P frameworks, as Gnutella, ar used for playacting discretional look (i.e., the condition of an investigation request isn't kept) and sorted out frameworks, like those reinforced Distributed Hash Table counts, ar used for playacting definite look (i.e., the condition of an assessment request is restricted)[1].

The consequent assessment issue oversees casual associations. In relational associations, individuals will honestly connect with specific partners that most likely have information concerning the advantages they're looking at for. during this paper, improvement of social models in $\mathrm{P} 2 \mathrm{P}$ getting sorted out is dependably investigated with thought on utilizing self-relationship to help the introduction of benefit exposure in gigantic scale $\mathrm{P} 2 \mathrm{P}$ frameworks [2]. 


\section{Search Unstructured Data Performance in P2P Networks Based on User Interest Model}

\section{RELATED WORKS}

To improve the pursuit execution in unstructured $\mathrm{P} 2 \mathrm{P}$ arranges, User Interest Model (UIM) is utilized to utilize the User's basic intrigue design. an exploration convention and a directing table change convention ar progressively arranged in order to facilitate the hunt strategy through self sorting out $\mathrm{P} 2 \mathrm{P}$ organize. furthermore to the momentum an avaricious convention has been wanted to drive the appropriated pursuit questioned records through companion's local cooperations. along these lines the hunt execution offered is impeccable. to help search execution, guided pursuit. The key drawback is the thing that data is really qualified to direct the pursuit. Utilized Interest-based neighborhood on the grounds that the general search steerage. the basic supposition that will be that if a friend $\mathrm{p} 0$ highlights an express document required by another companion $\mathrm{p}$, at that point $\mathrm{p} 0$ is most likely going to have various records to be mentioned by $\mathrm{p}$ inside what's to come. in step with past flourishing inquiries, alternate ways from peer $\mathrm{p}$ to numerous companions $\mathrm{p} 0$ ar set up in order to speed up ulterior pursuit forms.

Favorable circumstances OF arranged SYSTEM

- Guided Search.

- Routing change table.

- High level of optimality is accomplished exploitation this framework.

- Improved execution of search offered exploitation organize conventions in partner degree prudent way.

- Fast Search Technique upheld UIM.

\section{TECHNIQUE}

The hunt execution in unstructured P2P systems is successfully improved through abusing the applied science designs over client's normal intrigue.

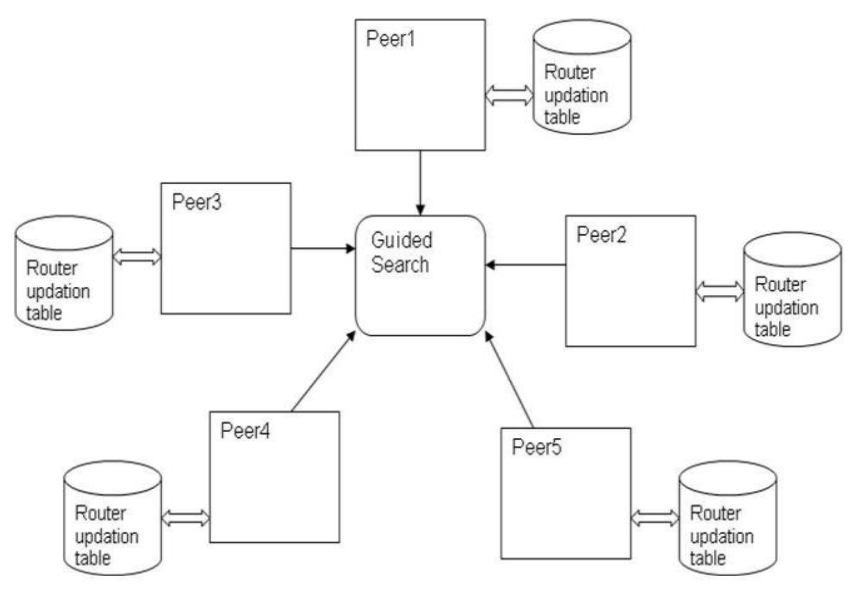

FIGURE 1 SYSTEM STRUCTURE

To improve the pursuit execution in unstructured $\mathrm{P} 2 \mathrm{P}$ systems bolstered the normal enthusiasm of the clients. territorially shared assets of a companion is investigated to direct the conveyed asset revelation strategy thus upgrade the general asset disclosure execution in unstructured $\mathrm{P} 2 \mathrm{P}$ systems .Uses the User Interest Model (UIM) bolstered the general probabilistic instrument named Condition Random Fields (CRF) to display client's different advantages.

On the off chance that the inquiry content is out there in local friend, at that point it'll recover the substance of the document from local framework. Else it advances the inquiry to its neighboring Peers. In the event that the neighboring companion have the pursuit content, at that point it reaction to watching out friend.

\section{RESULTS}

It's shown that search execution in unstructured P2P frameworks may be effectively improved through abusing the applied math models over customer's fundamental interest.

To improve the chase execution in unstructured P2P frameworks reinforced the fundamental eagerness of the customers. regionally shared resources of a friend may be examined to deal with the passed on resource disclosure methodology and along these lines redesign the benefit divulgence execution in unstructured P2P frameworks .Uses the User Interest Model (UIM) reinforced the general probabilistic instrument named Condition Random Fields (CRF) to show customer's different favorable circumstances.

If the request content is out there in neighborhood buddy, by then it'll recuperate the substance of the record from nearby system. Else it propels the request to its neighboring Peers. If the neighboring companion have the request content, by then it response to looking out friend.

Our answer toward overhauling search execution was offered in 3 phases.

1. A UIM has been familiar so also likewise with get customer's different favorable circumstances among a likelihood - theoretic Framework .It drives America to any present an inspiration of interest partition between any 2 companions.

2. guided by UIM, an anxious show has been foreseen to drive the dispersed chase of addressed reports through companion's neighborhood joint efforts.

3. Finally, a directing table change show has been foreseen to manage companion's neighbor records.

\section{V.CONCLUSION}

The hunt execution in unstructured P2P systems might be adequately improved through abusing the applied science designs over clients' normal advantages. Utilizations the User Interest Model (UIM) bolstered the general probabilistic device named Condition Random Fields (CRF) to show client's various advantages. With UIM, one will assess the probability of any companion sharing an exact document upon given verifiable actuality that it shares another file.With the help of a crisp presented separating instrument, the full P2P system can bit by bit self compose into atiny low world. 


\section{REFERENCES}

1. Kumaravel A., Meetei O.N.,An application of non-uniform cellular automata for efficient cryptography,2013 IEEE Conference on Information and Communication Technologies, ICT 2013,V-,I-,PP-1200-1205,Y-2013

2. Kumarave A., Rangarajan K.,Routing alogrithm over semi-regular tessellations,2013 IEEE Conference on Information and Communication Technologies, ICT 2013,V-,I-,PP-1180-1184,Y-2013

3. Dutta P., Kumaravel A.,A novel approach to trust based identification of leaders in social networks,Indian Journal of Science and Technology,V-9,I-10,PP--,Y-2016

4. Kumaravel A., Dutta P.,Application of Pca for context selection for collaborative filtering,Middle - East Journal of Scientific Research,V-20,I-1,PP-88-93,Y-2014

5. Kumaravel A., Rangarajan K.,Constructing an automaton for exploring dynamic labyrinths,2012 International Conference on Radar, Communication and Computing, ICRCC 2012,V-,I-,PP-161-165,Y-2012

6. Kumaravel A.,Comparison of two multi-classification approaches for detecting network attacks, World Applied Sciences Journal,V-27,I-11,PP-1461-1465,Y-2013

7. Tariq J., Kumaravel A.,Construction of cellular automata over hexagonal and triangular tessellations for path planning of multi-robots,2016 IEEE International Conference on Computational Intelligence and Computing Research, ICCIC 2016,V-,I-,PP--,Y-2017

8. Sudha M., Kumaravel A.,Analysis and measurement of wave guides using poisson method,Indonesian Journal of Electrical Engineering and Computer Science,V-8,I-2,PP-546-548,Y-2017

9. Ayyappan G., Nalini C., Kumaravel A.,Various approaches of knowledge transfer in academic social network,International Journal of Engineering and Technology,V-,I-,PP-2791-2794,Y-2017

10. Kaliyamurthie, K.P., Sivaraman, K., Ramesh, S. Imposing patient data privacy in wireless medical sensor networks through homomorphic cryptosystems 2016, Journal of Chemical and Pharmaceutical Sciences

11. Kaliyamurthie, K.P., Balasubramanian, P.C. An approach to multi secure to historical malformed documents using integer ripple transfiguration 2016 Journal of Chemical and Pharmaceutical Sciences 9

12. A.Sangeetha,C.Nalini,"Semantic Ranking based on keywords extractions in the web", International Journal of Engineering \& Technology, 7 (2.6) (2018) 290-292

13. S.V.GayathiriDevi,C.Nalini,N.Kumar,"An efficient software verification using multi-layered software verification tool "International Journal of Engineering \& Technology, 7(2.21)2018 454-457

14. C.Nalini,ShwtambariKharabe,"A Comparative Study On Different Techniques Used For Finger - Vein Authentication", International Journal Of Pure And Applied Mathematics, Volume 116 No. 8 2017, 327-333, Issn: 1314-3395

15. M.S. Vivekanandan and Dr. C. Rajabhushanam, "Enabling Privacy Protection and Content Assurance in Geo-Social Networks", International Journal of Innovative Research in Management, Engineering and Technology, Vol 3, Issue 4, pp. 49-55, April 2018.

16. Dr. C. Rajabhushanam, V. Karthik, and G. Vivek, "Elasticity in Cloud Computing", International Journal of Innovative Research in Management, Engineering and Technology, Vol 3, Issue 4, pp. 104-111, April 2018.

17. K. Rangaswamy and Dr. C. Rajabhushanamc, "CCN-Based Congestion Control Mechanism In Dynamic Networks", International Journal of Innovative Research in Management, Engineering and Technology, Vol 3, Issue 4, pp. 117-119, April 2018.

18. Kavitha, R., Nedunchelian, R., "Domain-specific Search engine optimization using healthcare ontology and a neural network backpropagation approach", 2017, Research Journal of Biotechnology, Special Issue 2:157-166

19. Kavitha, G., Kavitha, R., "An analysis to improve throughput of high-power hubs in mobile ad hoc network" , 2016, Journal of Chemical and Pharmaceutical Sciences, Vol-9, Issue-2: 361-363

20. Kavitha, G., Kavitha, R., "Dipping interference to supplement throughput in MANET", 2016, Journal of Chemical and Pharmaceutical Sciences, Vol-9, Issue-2: 357-360

21. Michael, G., Chandrasekar, A.,'Leader election based malicious detection and response system in MANET using mechanism design approach", Journal of Chemical and Pharmaceutical Sciences(JCPS) Volume 9 Issue 2, April - June 2016.

22. Michael, G., Chandrasekar, A.,'Modeling of detection of camouflaging worm using epidemic dynamic model and power spectral density", Journal of Chemical and Pharmaceutical Sciences(JCPS) Volume 9 Issue 2, April - June 2016

23. Pothumani, S., Sriram, M., Sridhar, J., Arul Selvan, G., Secure mobile agents communication on intranet,Journal of Chemical and Pharmaceutical Sciences, volume 9, Issue 3, Pg No S32-S35, 2016

24. Pothumani, S., Sriram, M., Sridhar, Various schemes for database encryption-a survey, Journal of Chemical and Pharmaceutical Sciences, volume 9, Issue 3, Pg NoS103-S106, 2016

25. Pothumani, S., Sriram, M., Sridhar, A novel economic framework for cloud and grid computing, Journal of Chemical and Pharmaceutical Sciences, volume 9, Issue 3, Pg No S29-S31, 2016

26. Priya, N., Sridhar, J., Sriram, M. "Ecommerce Transaction Security Challenges and Prevention Methods- New Approach” 2016 ,Journal of Chemical and Pharmaceutical Sciences, JCPS Volume 9 Issue 3.page no:S66-S68

27. Priya, N.,Sridhar,J.,Sriram, M."Vehicular cloud computing security issues and solutions" Journal of Chemical and Pharmaceutical Sciences(JCPS) Volume 9 Issue 2, April - June 2016

28. Priya, N., Sridhar, J., Sriram, M. "Mobile large data storage security in cloud computing environment-a new approach" JCPS Volume 9 Issue 2. April - June 2016

29. Anuradha.C, Khanna.V, "Improving network performance and security in WSN using decentralized hypothesis testing "Journal of Chemical and Pharmaceutical Sciences(JCPS) Volume 9 Issue 2, April - June 2016

\section{AUTHORS PROFILE}

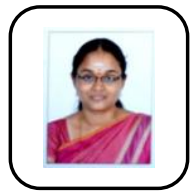

K.Shanmugapriya Assistant Professor, Department of Computer Science \& Engineering, Bharath Institute of Higher Education and Research, Chennai, India

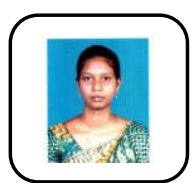

I. Mary Linda Assistant Professor, Department of Computer Science \& Engineering, Bharath Institute of Higher Education and Research, Chennai, India

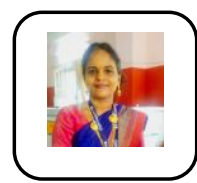

Kavitha G Assistant Professor, Department of Computer Science \& Engineering, Bharath Institute of Higher Education and Research, Chennai, India 